\title{
Intracranial Hemorrhage in a Neonate with Congenital Factor VII deficiency
}

\author{
Ranjan Kumar Pejaver ${ }^{1}$, Archana Bilagi ${ }^{1}$, Prakash HK$^{1}$ \\ ${ }^{1}$ St.Philomena's Hospital, Campbellroad, Mangalore, India.
}

\section{Abstract}

Congenital factor VII deficiency is a rare autosomal-recessive bleeding disorder. Clinical manifestations vary widely from asymptomatic subjects to life-theatening hemorrhages. Treatment options include fresh frozen plasma, prothrombin complex concentrates or plasma-derived FVII concentrates. We, hereby, present a case of 9 day old male neonate, admitted with multifocal seizures, lethargy, refusal to feed, and signs of raised intracranial tension. His prothrombin time was prolonged and CT head showed acute subdural hematoma with subarachnoid hemorrhage. His clotting factor assays, done in view of spontaneous intracranial hemorrhage, showed factor VII deficiency.

Keywords: Factor VII, Intracranial Hemorrhage, Neonate.

Corresponding Author: Dr. Prakash HK S/o HK Chandrashekar, Commission Agent, Plot No 7, Shop No 53,Rajendra Gunj, Raichur 5841101, Karnataka. Mob. No: 9845410673

Received: March 2018

Accepted: March 2018

\section{Introduction}

Factor VII is one of the vitamin $\mathrm{K}$-dependent coagulation factors synthesized in the liver. It is present in plasma in low concentrations $(0.5 \mathrm{mcg} / \mathrm{ml})$ and has a short circulating halflife of 3-4 hours. Inherited factor VII deficiency is a rare autosomal recessive disorder with estimated incidence of $1 / 500,000$ among the general population. ${ }^{[1]}$ Affected pateints may remain asymtomatic for a long time or may present with bleeding manifestations. Intracranial bleeding is comparatively more common in factor VII deficiency than with other coagulation defects and they usaully occur in first six months of life. Very few cases with cangenital factor VII deficiency and intracranial hemorrhage have been reported. Therfore, we report such a rare case who presented with intracranial hemorrhage.

\section{Case Report}

A term male neonate, born to 2 nd degree consanguineously married couple through caesarean section, with uneventful immediate postnatal life. His birth weight was $2.6 \mathrm{kgs}$. Baby presented to us on day 9 of life with multifocal seizures, vomiting and refusal to feed along with inconsolable cry. Clinical examination revealed signs of raised intracranial tension (lethargy, bulging anterior fontanel, generalized hypotonia, exaggerated DTRs, absent Moro's and sucking reflexes). His septic workup including blood and CSF culture was negative. Other investigations showed hyponatremia with normal glucose and calcium levels and adequate platelet counts. Coagulation profile showed prolonged prothrombin time (PT) with normal activated partial thromboplastin time (aPTT). Liver function tests and d-dimer assays were normal. CT Brain showed acute subdural hematoma in occipital region with subarachnoid hemorrhage along with infarct involving posterior cerebral artery territory. Magnetic resonance arteriogram (MRV) and MR Venogram (MRV) done to rule out the arterio-venous malformations and thrombosis showed same findings as on CT scan. Supportive management was started along with vitamin K1 injections, FFP Transfusions and anticonvulsants. Although, baby had neurological improvement after 3 days; prothrombin time remained prolonged inspite of FFP transfusions. Therefore, primary coagulation disorder (clotting factor VII deficiency) was suspected in view of prolonged prothrombin time and spontaneous intracranial hemorrhage. Baby was discharged on day 26 of life with the plan of follow up to confirm the diagnosis. But the baby again brought on day 28 of life, within 48 hours of discontinuation of FFP with inconsolable cry and seizures. His PT was still prolonged $(3 \mathrm{~min})$ with normal aPTT. Mixing studies showed prolonged PT which could be corrected by control plasma and aged serum. Repeat CT brain showed new subdural hematoma in frontal region along with sulcal hemorrhage, ischemic changes in PCA territory. Lateron, the dignosis of coagulation disorder was confirmed by factor assays done after 72 hours of FFP discontinuation at 2 months of age, which revealed very low factor VII level $(<0.01 \%)$ along with normal Factor VIII and IX assays. Baby was managed aggressively with 6 hrly FFP transfusions alongwith other supportive measures for one week. FFP transfusions were gradually weaned down to 
every alternate day for 2 weeks and presently FFP transfusion is being given 2-3 times/week with oral anti convulsants. There was neurological improvement after 3-4 days and at present he is neurologically intact with normal milestones and no evidence of muscle weakness.

\section{Discussion \& Conclusion}

Factor VII Deficiency is the most frequent among rare congenital bleeding disorders and inherited as autosomal recessive disorder, with $\mathrm{M}: \mathrm{F}$ ratio of 1:1 .This disorder accounts for one symptomatic individual per 500,000 population apparently without any racial and ethnic predilection. ${ }^{[1]}$ Clinical heterogeneity is the hallmark of this hemorrhagic disorder; the severity ranges from mild and asymptomatic forms to lethal ones. The correlation between FVII coagulation activity (FVII: C) and bleeding tendency appears to be poor. ${ }^{[2,3]}$ FVII deficiency is the only congenital bleeding disorder characterized by isolated prolonged prothrombin time. Clinically congenital factor VII deficiency can be divided into following categories - 1) Severe - presenting with at least one of the following symptoms: GI, CNS bleeding or haemarthrosis with or without other bleeds2)

Moderate - have three or more symptoms with the exception of GI, CNS bleeding or haemarthrosis 3) Mild - have one or two symptoms with the exception of GI, CNS bleeding or haemarthrosis 4) Asymptomatic - detected only by investigations. ${ }^{[4,5]}$ Factor VII Deficiency is the only disorder with isolated prolonged Prothrombin time with normal activated partial thromboplastin time. ${ }^{[5]}$ Diagnosis is confirmed by doing Factor VII Assays. Prenatal diagnosis is available and should be proposed only when a family history with severe bleeding is present. Cord blood is usually obtained by either the trans-abdominal or trans-amniotic approach, and genetic analysis performed on blood samples is the gold standard method. ${ }^{[6-8]}$ Substitution therapy is the main therapeutic option of inherited FVII deficiency in severe cases and when bleeding history is present. Table 1 outlines the various treatment options available. ${ }^{[9-13]}$

Recombinant factor VII when given at an average dose of $20 \mu \mathrm{g} / \mathrm{kg}$ has been observed to be effective when repeatedly administrated until haemostasis is achieved, but optimal treatment schedules have still not been defined.

Unlike the haemophilias, prophylaxis is not a common practice in FVII-deficient patients; it is mainly used in unweaned infants who are prone to severe and frequent bleedings. However, preliminary reports suggest that prophylaxis may also be effective in scenarios such as menorrhagia with iron deficiency and in patients with recurrent haemarthrosis. ${ }^{[14]}$ Continuous infusion of rFVIIa in surgical procedures performed in FVII-deficient patients has been reported. When properly treated, FVII deficiency is a disease with good prognosis and a life expectancy similar to that of normal individuals.
A non-replacement therapeutic approach to congenital clotting defects is a pioneering challenge in the field of blood coagulation, and treatment strategies other than gene therapy have been proposed with the aim of improving the clinical phenotype of severely FVII-deficient patients. Experimental evidence exists regarding the ability of certain aminoglycosides to suppress premature termination of translation by non-sense mutation in a number of diseases, including hemophilia B. Recently, a similar observation was reported both in cellular models and in vivo in patients with severe FVII deficiency because of non-sense mutations associated with a life-threatening bleeding tendency. ${ }^{[12,13]}$

Table 1: Products available for FVII treatment
\begin{tabular}{|l|l|l|l|l|}
\hline Products & Potency & \multicolumn{2}{|l|}{ Advantages } & Disadvantages \\
\hline FFP & 1 & $\begin{array}{l}\text { Cheap, Easily } \\
\text { availablc }\end{array}$ & Volume overload \\
\hline $\begin{array}{l}\text { PCC( } \\
\text { Prothrombin }\end{array}$ & $5-10$ & $\begin{array}{l}\text { Suitable for } \\
\text { surgery }\end{array}$ & Risk of thrombosis \\
\hline Complex Concentrate & $\begin{array}{l}\text { Suitable for } \\
\text { surgery }\end{array}$ & $\begin{array}{l}\text { Less } \\
\text { effective }\end{array}$ & \\
\hline $\begin{array}{l}\text { PdVII (Plasma } \\
\text { derived ) }\end{array}$ & $20-40$ & $\begin{array}{l}\text { Effective, No } \\
\text { risk of viral }\end{array}$ & Expensive, & $\begin{array}{l}\text { Not } \\
\text { easily }\end{array}$ \\
\hline $\begin{array}{l}\text { rVIIa } \\
\text { Recombinant } \\
\text { Factor }\end{array}$ & $>25000$ & transmission & availability & \\
\hline VII) & & & & \\
\hline
\end{tabular}

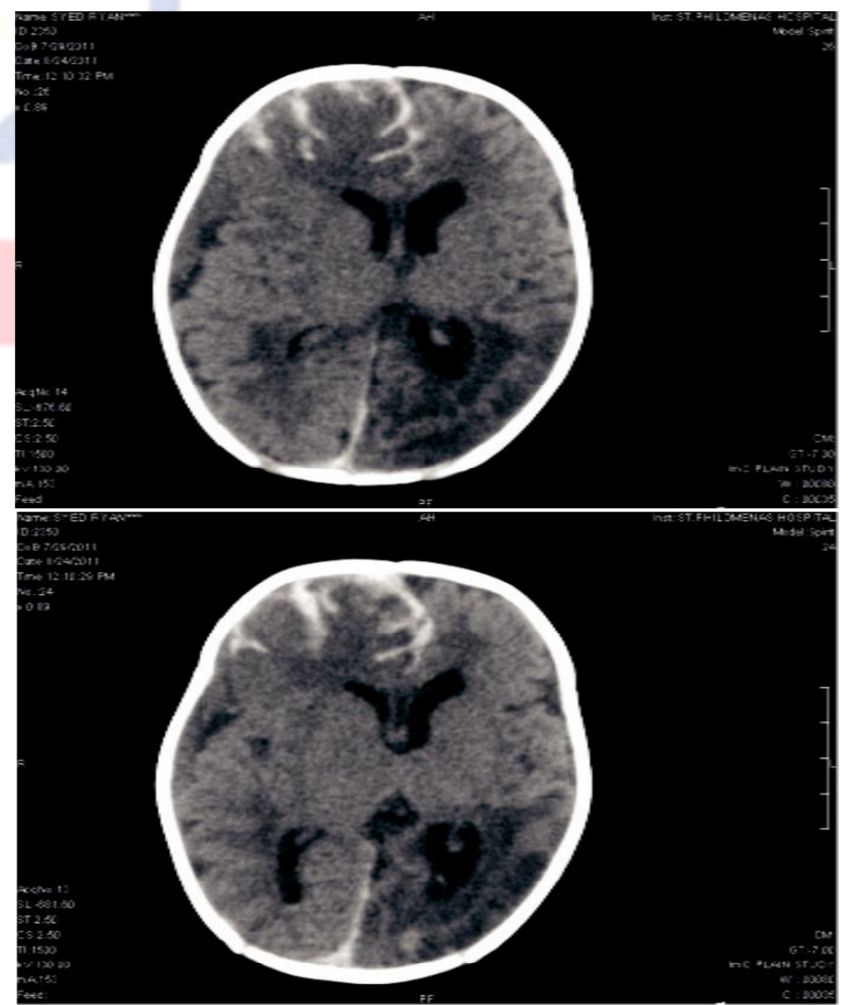

Figure 1: (CT images of Brain Showing acute subdural hematoma in occipital region with subarachnoid hemorrhage along with infarct involving posterior cerebral artery territory). 


\section{Pejaver et al; Intracranial Hemarrhage in a Neanate}

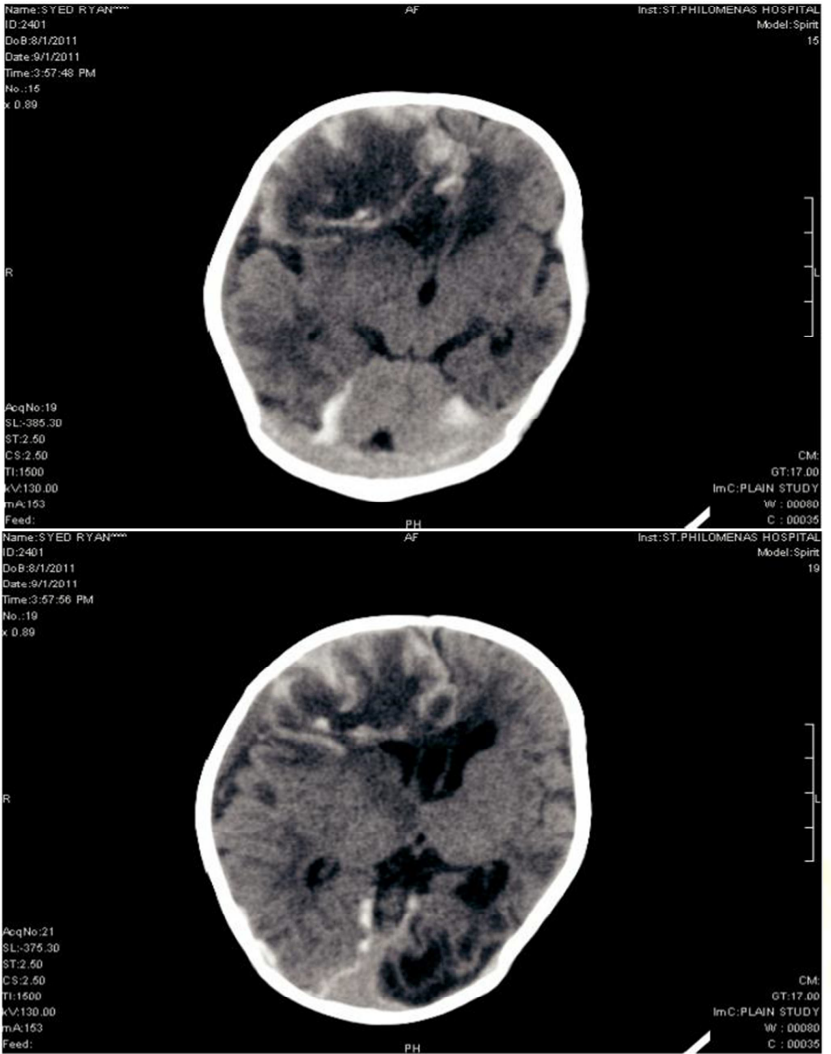

Figure 2: Repeat CT images of Brain done after 2days of discontinuation of FFP, Shows new subdural hematoma along with infarct involving posterior cerebral artery territory.

\section{References}

1. Mannucci PM, Duga S, Peyvandi F. Recessively inherited coagulation disorders. Blood 2004;104:1243-52.
2. Giansily-Blaizot $\mathrm{M}$, Biron-Andreani $\mathrm{C}$, Aguilar-Martinez $\mathrm{P}$ et al. Inherited factor VII deficiency and surgery: clinical data are the best criteria to predict the risk of bleeding. Br J Haematol 2002;117:172-5.

3. Barnett JM, Demel KC, Mega AE, Butera JN, SweeneyJD. Lack of bleeding in patients with severe factor VII deficiency. Am J Hematol 2005;78:134-7.

4. Giansily-Blaizot M, Verdier R, Biron-Adre'ani $\mathrm{C}$ et al.Analysis of biological phenotypes from 42 patients with inherited factor VII deficiency: can biological tests predict the bleeding risk? Haematologica 2004;89:704-9.

5. Mariani G, Dolce A, Marchetti G, Bernardi F. Clinical picture and management of congenital factor VII deficiency.

Haemophilia 2004;10(Suppl 4):180-3.

6. Shetty S, Ghosh K. Robustness of factor assays following cordocentesis in the prenatal diagnosis of haemophilia and other bleeding disorders. Haemophilia 2007;13:172-7.

7. Mota L, Ghosh K, Shetty S. Second trimester antenatal diagnosis in rare coagulation factor deficiencies.J Pediatr Hematol Oncol 2007;29:137-9.

8. Giansily-Blaizot M, Aguilar-Martinez P, Mazurier C et al. Prenatal diagnosis of severe factor VII deficiency using mutation detection and linkage analysis. Br J Haematol 2001;112:251-2.

9. Berrettini M, Mariani G, Schiavoni $M$ et al. Pharmacokinetic evaluation of recombinant, activated factorVII in patients with inherited factor VII deficiency.Haematologica 2001; 86: 640-5.

10. Ingerslev J, Kristensen HL. Clinical picture and treatment strategiesin factor VII deficiency . Haemophilia 1998;4:689-96.

11. Mariani G, Konkle BA, Ingerslev J. Congenital factor VII deficiency: therapy with recombinant activated factor VII - a critical appraisal. Haemophilia 2006;12:19-27.

12. Mariani G, Lapecorella M, Dolce A. Steps towards an effective treatment strategy in congenital factorVII deficiency. Semin Hematol 2006; 1(Suppl 1):S42-S4

13. Lapecorella M, Mariani G; International Registry on Congenital Factor VII Deficiency. Factor VII deficiency: defining the clinical picture and optimizing therapeutic options. Haemophilia 2008;14(6):1170-5.

14. Napolitano M, Giansily-Blaizot M, Dolce $\Lambda$, Schved JF, $\Lambda$ uerswald $\mathrm{G}$, Ingerslev $\mathrm{J}$, et al. Prophylaxis in congenital factor VII deficiency: indications, efficacy and safety. Results from the Seven Treatment Evaluation Registry (STER). Haematologica. 2013 Feb 12. [Epub ahead of print]

Copyright: (c) the author(s), publisher. Asian Journal of Clinical Pediatrics and Neonatology is an Official Publication of "Society for Health Care \& Research Development". It is an open-access article distributed under the terms of the Creative Commons Attribution NonCommercial License, which permits unrestricted non-commercial use, distribution, and reproduction in any medium, provided the original work is properly cited.

How to cite this article: Pejaver RK, Bilagi A, Prakash HK. Intracranial Hemorrhage in a Neonate with Congenital Factor VII deficiency. Asian J. Clin. Pediatr. Neonatol.2018;6(1):6-8.

DOI: dx.doi.org/10.21276/ajcpn.2018.6.1.3

Source of Support: Nil, Conflict of Interest: None declared. 